\title{
Considerations on the Convenience of Distilling at High Proof in Continuous Alcoholic Distillation for Beverages
}

\author{
Herminio M. Brau

\section{INTRODUCTION}

Recently published results on studies conducted at this Rum Pilot Plant on the distribution of fusel oil along the plates of continuous distillation columns under different operating conditions, suggested the convenience of withdrawing the product from a point as high as possible along the column (1). ${ }^{2}$ The data obtained indicate that, under any set of operating conditions, the higher the plate in the column, and, consequently, the higher the proof of the product, the lower would be the concentration of fusel oil in the latter. Because of the adverse effect of the oil on the quality of the finished product, the production of distillates of low fusel-oil content is most desirable in the industrial production of alcoholic beverages, especially in the case of light-type beverages such as Puerto Rican rum.

Table 1 presents selected data on fusel-oil distribution along the plates of a rectifying column containing 50 bubble-cap trays under different operating conditions (1). The data presented correspond to concentrations of the order of $10,000 \mathrm{mg}$. of fusel oil, expressed as amyl alcohol per 100 $\mathrm{ml}$. of sample, at the plate of maximum accumulation. Large accumulations occur at several plates around the feed plate, which was plate 18 in all cases, with maximum accumulations occurring at plates 2 to 6 above the feed plate, depending on the operating conditions.

Two important considerations should be kept in mind before deciding that the most convenient practice would be that of removing the productstream from the highest point of the column at the highest possible proof, as suggested by the results mentioned above. The dispositions of the Spirits and Alcoholic Beverages Act of Puerto Rico is the first point to be considered. This Act establishes that spirituous distillates should be produced at an alcoholic content below $190^{\circ}$ proof in order to qualify as

${ }^{1}$ Chemical Engineer, Agricultural Experiment Station, University of Puerto Rico, Río Piedras, P.R. The author wishes to express his deepest apprecintion to Víctor Rodriguez Benítez, Technical Director, and to Juan D. Curet, Chemist, of the Rum Pilot Plant of this Station, for valuable suggestions and revision of the manuscript; and to Mydiah Medina de Mariani, Cruz Aguilera Flores, Ricarte D. Rivera, Amador Belardo Yadós, Romualdo Fraticelli, and Belén M. Camacho, of the Chemistry Section of the Rum l'ilot Plant, for their valued assistance in the analytical work required in these studies.

${ }^{2}$ Italic numbers in parentheses refers to Iiterature Cited, p. 257. 
rum. The U. S. Spirits and Alchoholic Beverages Act establishes that, in order to be considered as whiskey, spirituous distillates should be produced at an alcoholic content helow $160^{\circ}$ proof.

The second point to be considered is the recovery of desirable congeneric substances, such as esters and acids, which are of utmost importance since

TABLE 1.-Fusel-oil distribution in rectifying column under different operating conditions ${ }^{1}$

\begin{tabular}{|c|c|c|c|c|c|c|c|c|c|c|c|c|c|}
\hline \multirow{2}{*}{$\frac{\stackrel{g}{g}}{\mu}$} & \multicolumn{3}{|c|}{$\begin{array}{c}\text { Feed2: 20-percent } \\
\text { alcolhol by volume } \\
\text { for reflux ratio indicated }\end{array}$} & \multicolumn{4}{|c|}{$\begin{array}{l}\text { Fecd2: } 30 \text {-percent alcolol by } \\
\text { volume for reflux ratio indicated }\end{array}$} & \multicolumn{3}{|c|}{$\begin{array}{l}\text { Feed": } 40 \text {-percent } \\
\text { alcolool by volume } \\
\text { for reflux ratio } \\
\text { indicated }\end{array}$} & \multicolumn{3}{|c|}{$\begin{array}{l}\text { Feed²: 50-percent } \\
\text { alcohol by volume } \\
\text { for reflux ratio } \\
\text { indicated }\end{array}$} \\
\hline & $5: 1$ & $4: 1$ & 3:1 & 15:1 & 10:1 & $5: 1$ & $4: 1$ & $5: 1$ & $4: 1$ & $3: 1$ & $5: 1$ & $4: 1$ & $3: 1$ \\
\hline 50 & 15 & 5 & 20 & 5 & 5 & 15 & 20 & 10 & 10 & 10 & 10 & 15 & 10 \\
\hline 42 & 25 & 45 & 120 & 5 & 10 & 20 & 45 & 15 & 25 & 65 & 15 & 25 & 65 \\
\hline 38 & 65 & 150 & 500 & 15 & 20 & 50 & 110 & 55 & 110 & 400 & 40 & 75 & 305 \\
\hline 34 & 250 & 550 & 2,000 & 45 & 100 & 195 & 400 & 190 & 395 & 500 & 180 & 360 & 900 \\
\hline 30 & 800 & 1,900 & 4,000 & 235 & 480 & 850 & 1,400 & 1,050 & 1,150 & 2,500 & 690 & 1,050 & 2,000 \\
\hline 26 & 4,000 & 5,500 & 7,000 & 950 & 2,200 & 2,950 & 4,000 & 2,800 & 3,700 & 5,500 & 2,350 & 3,000 & 4,200 \\
\hline 24 & 6,500 & 8,000 & 9,500 & 2,600 & 3,950 & 6,050 & 6,500 & 5,850 & 6,400 & 7,500 & 3,900 & 4,250 & 6,300 \\
\hline 23 & 8,000 & 10,000 & 9,500 & 5,000 & 6,000 & 8,000 & 8,000 & 7,850 & $8,250 \mid$ & 8,500 & 5,200 & 5,600 & 8,250 \\
\hline 22 & 10,000 & 10,500 & 9,000 & 7,100 & 7,400 & 10,500 & 9,000 & 8,500 & 9,500 & 9,000 & 6,700 & 6,900 & 8,400 \\
\hline 21 & 11,500 & 9,500 & 6,500 & 8,500 & 9,700 & 11,400 & 9,000 & 9,700 & 9,850 & 7,000 & 8,900 & 8,900 & 9,400 \\
\hline 20 & 11,000 & 8,000 & 4,500 & 10,750 & 10,300 & 10,500 & 8,000 & 11,000 & 9,800 & 5,500 & 9,770 & 9,040 & 8,550 \\
\hline 19 & 4,000 & 2,500 & 1,000 & 7,100 & 7,400 & 2,450 & 3,500 & 7,000 & 4,850 & 2,250 & 9,240 & 8,470 & 7,650 \\
\hline 18 & 950 & 500 & 300 & 1,150 & 1,250 & 800 & 1,400 & 2,150 & 800 & 770 & 4,300 & 4,100 & 2,500 \\
\hline 17 & 550 & 300 & 250 & 510 & 640 & 470 & 700 & 890 & 625 & 550 & 1,650 & $2,300 \mid$ & 1,500 \\
\hline 16 & 200 & 90 & 95 & 95 & 100 & 160 & 300 & 210 & 120 & 200 & 410 & 580 & 535 \\
\hline 15 & 95 & 55 & 55 & 30 & 35 & 70 & 100 & 70 & 75 & 80 & 100 & 140 & 115 \\
\hline 14 & 65 & 35 & 40 & 10 & 10 & 45 & 80 & 60 & 45 & 40 & 30 & 50 & 45 \\
\hline 12 & 30 & 25 & 35 & 0 & 0 & 15 & 35 & 30 & 40 & 10 & 0 & 5 & 0 \\
\hline 8 & 15 & 10 & 20 & 0 & 0 & 10 & 15 & 30 & 35 & 0 & 0 & 0 & 0 \\
\hline 4 & 5 & 5 & 10 & 0 & 0 & I & & 35 & 45 & 0 & & 0 & 0 \\
\hline
\end{tabular}

1 Data in mg. of fusel oil as amyl alcohol per $100 \mathrm{ml}$. of sample.

2 Feed was added at plate 18 in all cases.

it is their characteristic body, aroma and taste, developed through complex chemical reactions and physical interactions occurring during the aging process, that differentiate alcoholic beverages from industrial alcohol.

\section{OBJECTIVE}

There are no data in the technical literature on the distribution of congeneric substances along continuous distillation columns in the process of manufacture of spirituous beverages from molasses. Theoretical considerations indicate that the concentration of volatile congeneric substances 
would continuously increase toward the upper end of the column reaching a maximum concentration in the overhead distillate. There is no information regarding the possible accumulation of heavier congeneric substances at plates of lower alcoholic concentrations in the column. Several experiments were conducted in order to obtain experimental data on the distribution of congeneric substances along the plates of the rectifying column of the continuous distillation unit of this Plant.

\section{EXPERIMENTAL PROCEDURE}

Raw distillate from the beer column of the continuous distillation unit was diluted with water to an alcoholic strength of $80^{\circ}$ proof at $60^{\circ} \mathrm{F}$. in all cases. This $80^{\circ}$-proof alcohol solution was fed to plate 12 , from bottom up, of a 50-bubble-cap tray rectifying column without processing it in the purifying column. The rectifying column was operated at reflux ratios of $15: 1,10: 1,7: 1,5: 1$, and $4: 1$ in successive experiments. Reflux ratio is defined as the volumetric ratio between the reflux stream returned to the top of the column and the main-product side-stream. The main product was removed as a liquid side-stream from plate 42 in all cases. A heads-product stream, containing about 3 percent of the alcohol fed, was removed from the overhead distillate. A fusel-oil side-stream was removed from plate 14 in all experiments. Samples were taken from plates $50,48,46,44,42$, 40,38 , and 36 at 4 and 8 hours after withdrawal of main product commenced. No samples were taken below this point since the region of very high concentration of fusel oil and other unidentified tail substances is approached. Very high concentrations of fusel oil and tail substances render the product undrinkable.

All samples were analyzed to determine their alcoholic strength as well as their contents of esters, acids, and aldehydes.

An additional experiment was conducted at a reflux ratio of 5:1 with the objective of determining whether there is any accumulation of congeneric substances, other than fusel oil, in regions of lower alcoholic content.

In this experiment samples were taken from plates $50,46,42,40,38,36$, $34,32,30,28,26,24,22,20,18,16,14,10,6$, and 2 at 8 hours after withdrawal of main product commenced. All samples were analyzed to determine their alcoholic strength as well as their contents of esters, acids, and aldehydes.

\section{EQUIPMENT UTILIZED}

The experimental work reported in this paper was conducted utilizing the rectifying column of the continuous distillation unit of the Rum Pilot Plant of this Station. This column contains 50 bubble-cap plates, 15" nominal diameter at $12^{\prime \prime}$ plate-spacing. The column is provided with a total condenser and a reflux collector from which the reflux and the heads- 
product streams are removed. The reboiler of the column is an outside shell and tube evaporator utilizing indirect steam. A steam heater is installed in the feed line to maintain a constant temperature in the feed. All plates of the column are provided with sampling facilities. In addition, the column is provided with numerous automatic and manual control instruments as described below.

\section{CONTROL SYSTEM UTILIZED}

The control system utilized includes automatic temperature controllers to regulate the temperature of the feed and reflux streams at any desired value. The boil-up rate of the column is controlled by an automatic differential-pressure controller which, in turn, resets an automatic steam flow-rate controller to the reboiler. The differential-pressure instrument is tapped near the bottom and top ends of the column. The rate of flow of the reflux, heads, and main-product streams are automatically controlled in all cases. The flow of the bottom product is regulated by an automatic level controller which maintains enough liquid in the column to cover the tubes of the reboiler. The control system utilized in the course of these studies for the operation of the rectifying column was that developed at this Plant; it consists of varying the rate of feed to the column in order to maintain constant a reference temperature in the plate just above the feed plate (2). By selecting the appropriate reference-temperature value, the liquid flowing from the plate just above the feed plate, which mixes with the feed in the downtake, has approximately the same composition as the feed itself. By maintaining constant all the variables which affect the distribution of compositions at the enriching section of the column, it is possible to obtain very stable compositions in said enriching section from which the main-product and byproduct streams are removed.

\section{RESULTS}

The results of these studies are presented on tables 2 to 7 . The data of tables 2 to 6 , on the distribution of congenerics in the upper region of the column, definitely indicate that the concentration of congenerics in the plates of the column increases, the higher the plate, reaching a maximum in the overhead distillate. There is no indication of any accumulation of congeneric substances in intermediate plates of this region of high alcoholic strengths. The absolute concentration of each particular congeneric at the various plates of the column will depend on the composition of the feed as well as on the operating conditions utilized. The data obtained indicate, however, that, irrespective of the magnitude of the concentration of the various congenerics, there will always be a greater concentration of these substances the higher the plate in the column.

The results in table 7, which correspond to the experiment conducted 
with the objective of exploring other regions of the column, also indicate that there is no significant accumulation of congeneric substances at

Table 2.-Distribulion of conyenerics in rectifying column for these experimental condilions: Feed-40-percent alcohol at plate 12; reflux ratio-15:1; product-plate $42^{1}$

\begin{tabular}{c|r|r|r|r|r|r|r|r}
\hline \multirow{2}{*}{ Plate } & \multicolumn{5}{|c|}{ 4-hour samples } & \multicolumn{5}{|c}{ 8-hour samples } \\
\cline { 2 - 7 } \cline { 3 - 7 } & Alcohol & Aldehydes & Acids & Esters & Alcohol & Aldehydes & Acids & Esters \\
\hline Heads & 192.7 & 150.7 & 2.2 & 26.7 & 193.2 & 105.5 & 4.1 & 20.4 \\
50 & 193.6 & 85.9 & 2.2 & 21.0 & 193.4 & 66.5 & 1.0 & 10.1 \\
48 & 193.6 & 49.2 & 1.6 & 7.9 & 193.1 & 44.8 & .7 & 3.2 \\
46 & 193.4 & 33.5 & .5 & 2.7 & 193.1 & 26.3 & .5 & 1.6 \\
44 & 193.2 & 22.5 & .4 & 2.7 & 192.9 & 19.6 & .4 & 0 \\
42 & 192.9 & 15.3 & .4 & 1.7 & 192.7 & 14.2 & .4 & 0 \\
40 & 192.5 & 12.1 & .2 & 2.5 & 192.5 & 10.6 & .4 & 0 \\
38 & 192.3 & 10.6 & .2 & .8 & 192.3 & 7.4 & .4 & 0 \\
36 & 192.2 & 7.8 & .2 & .5 & 191.8 & 5.9 & .2 & 0 \\
\hline
\end{tabular}

1 The alcohol is expressed in degrees proof at $60^{\circ} \mathrm{F}$; the concentration of aldehydes, acids, and esters is expressed, respectively, as milligrams of acetaldehyde, acetic acid, and ethyl acetate per $100 \mathrm{ml}$. of sample.

TABLE 3.-Distribution of congenerics in rectifying column for these experimental conditions: Feed-40-percent alcohol at plate 12; reflux ratio-10:1;

product-plate $42^{1}$

\begin{tabular}{c|r|r|r|r|r|r|r|r}
\hline \multirow{2}{*}{ Plate } & \multicolumn{5}{|c|}{ 4-hour samples } & \multicolumn{5}{|c}{ 8-hour samples } \\
\cline { 2 - 9 } & Alcohol & Aldehydes & Acids & Esters & Alcohol & Aldehydes & Acids & Esters \\
\hline Heads & 192.1 & 176.0 & 2.3 & 38.3 & 193.2 & 198.7 & 2.9 & 42.7 \\
50 & 193.2 & 98.6 & .8 & 18.7 & 193.4 & 110.4 & .6 & 22.4 \\
48 & 193.1 & 55.9 & .5 & 6.1 & 193.2 & 62.0 & .6 & 10.3 \\
46 & 193.0 & 38.1 & .5 & .2 & 193.1 & 36.2 & .4 & .8 \\
44 & 192.8 & 22.1 & .4 & .2 & 192.9 & 21.7 & .4 & 0 \\
42 & 192.6 & 14.9 & .4 & .3 & 192.6 & 16.0 & .4 & 0 \\
40 & 192.1 & 10.8 & .4 & .4 & 192.3 & 10.9 & .4 & 0 \\
38 & 192.0 & 8.8 & .2 & .3 & 192.0 & 8.2 & .4 & 0 \\
36 & 191.5 & 6.6 & .2 & .2 & 191.2 & 5.9 & .4 & 0 \\
\hline
\end{tabular}

1 The alcohol is expressed in degrees proof at $60^{\circ} \mathrm{F}$; the concentration of aldehydes, acids, and esters is expressed, respectively, as milligrams of acetaldehyde, acetic acid, and ethyl acetate per $100 \mathrm{ml}$. of sample.

intermediate plates of columns, with the exception of the esters. In this latter case the data of table 7 show that there is some accumulation of esters at plates of high fusel-oil accumulation, i.e., several plates around 
the feed plate, which was plate 12 in this experiment. The data of table 1 indicate that this is precisely the region of maximum fusel-oil accumulation.

TABLE 4.-Distribution of congenerics in rectifying column for these experimental conditions: Feed-40-percent alcohol at plate 12; reflux ratio-7:1; product-plate $4^{1}$

\begin{tabular}{c|r|r|r|r|r|r|r|r}
\hline \multirow{2}{*}{ Plates } & \multicolumn{5}{|c|}{ 4-hour sumples } & \multicolumn{4}{|c}{ 8-hour samples } \\
\cline { 2 - 9 } & Alcohol & Aldehydes & Acids & Esters & Alcohol & Aldehydes & Acids & Esters \\
\hline Heads & 192.0 & 232.9 & 2.0 & 52.0 & 192.9 & 199.7 & 3.2 & 43.6 \\
50 & 193.0 & 137.4 & 1.2 & 27.3 & 193.2 & 110.9 & .7 & 25.0 \\
48 & 192.9 & 81.3 & .8 & 4.4 & 193.0 & 67.3 & .6 & 13.7 \\
46 & 192.8 & 50.2 & .5 & .7 & 192.6 & 38.2 & .5 & .6 \\
44 & 192.6 & 31.4 & .4 & .8 & 192.2 & 24.0 & .5 & .2 \\
42 & 192.0 & 18.5 & .2 & .8 & 192.0 & 15.3 & .5 & 0 \\
40 & 191.4 & 11.2 & .2 & .2 & 191.5 & 11.0 & .5 & 0 \\
38 & 191.1 & 7.6 & .2 & .2 & 190.9 & 8.5 & .4 & 0 \\
36 & 190.4 & 6.8 & .2 & .3 & 190.5 & 7.3 & .4 & 0 \\
\hline
\end{tabular}

${ }^{1}$ The alcohol is expressed in degrees proof at $60^{\circ} \mathrm{F}$; the concentration of aldehydes, acids and esters is expressed, respectively, as milligrams of acetaldehyde, acetic acid, and ethyl acetate per $100 \mathrm{ml}$. of sample.

TABLE 5.-Distribution of congenerics in rectifying column for these experimental conditions: Feed-40-percent alcohol at plate 12; reflux ratio-5:1; product-plate $42^{1}$

\begin{tabular}{|c|c|c|c|c|c|c|c|c|}
\hline \multirow{2}{*}{ Plate } & \multicolumn{4}{|c|}{ 4-hour samples } & \multicolumn{4}{|c|}{ 8-hour samples } \\
\hline & Alcohol & Aldehydes & Acids & Esters & Alcohol & Aldehydes & Acids & Esters \\
\hline Heads & 191.4 & 207.9 & 1.1 & 42.2 & 191.9 & 309.1 & 1.6 & 70.2 \\
\hline 50 & 193.0 & 112.0 & .8 & 24.0 & 192.8 & 162.5 & 1.2 & 41.9 \\
\hline 48 & 192.7 & 60.6 & .6 & 12.2 & 192.6 & 91.4 & .7 & 22.8 \\
\hline 46 & 192.3 & 35.1 & .5 & 6.8 & 192.3 & 50.6 & .7 & 7.5 \\
\hline 44 & 191.9 & 20.8 & .5 & 1.7 & 191.9 & 27.8 & .5 & 4.0 \\
\hline 42 & 191.5 & 13.6 & .5 & 1.4 & 191.3 & 18.3 & .5 & .6 \\
\hline 40 & 190.5 & 8.8 & .5 & 1.4 & 190.6 & 11.0 & .5 & .2 \\
\hline 38 & 189.7 & 6.4 & .5 & .6 & 189.5 & 8.4 & .5 & 0 \\
\hline 36 & 189.2 & 5.8 & .5 & - & 189.0 & 6.0 & .5 & 0 \\
\hline
\end{tabular}

1 The alcohol is expressed in degrees proof at $60^{\circ} \mathrm{F}$.; the concentration of aldehydes, acids, and esters is expressed, respectively, as milligrams of acetaldehyde, acetic acid, and ethyl acetate per $100 \mathrm{ml}$. of sample.

It should be kept in mind that plate 18 was the feed plate on the experiments reported in table 1.

The nauseating taste and odor of the liquid accumulating in this region 
TABLE 6.-Distribution of congenerics in rectifying column for these expcrimental conditions: Feed-40-percent alcohol al plate 12; reflux ratio-4:1; product-plate $42^{2}$

\begin{tabular}{c|r|r|r|r|r|r|r|r}
\hline \multirow{2}{*}{ Plate } & \multicolumn{5}{|c|}{ 4-hour samples } & \multicolumn{5}{|c}{ 8-hour Sample } \\
\cline { 2 - 7 } & Alcohol & Aldehydes & Acids & Esters & Alcohol & Aldehydes & Acids & Esters \\
\hline Heads & 191.4 & 225.0 & 2.2 & 56.8 & 192.7 & 227.9 & 3.5 & 79.8 \\
50 & 192.3 & 120.6 & 1.4 & 33.3 & 192.7 & 124.4 & 2.3 & 50.0 \\
48 & 192.2 & 69.0 & 1.0 & 16.6 & 192.2 & 73.9 & 1.4 & 24.6 \\
46 & 191.8 & 40.2 & .6 & 5.3 & 191.8 & 43.7 & .7 & 4.8 \\
44 & 191.0 & 23.6 & .4 & 4.8 & 191.4 & 24.2 & .5 & .5 \\
42 & 190.3 & 14.0 & .4 & 2.6 & 190.6 & 16.2 & .5 & 0 \\
40 & 189.4 & 10.3 & .2 & 2.0 & 190.0 & 10.6 & .5 & 0 \\
38 & 188.3 & 7.8 & .2 & 1.6 & 189.1 & 8.6 & .4 & 0 \\
36 & 187.2 & 5.0 & .2 & 1.2 & 188.3 & 6.9 & .4 & 0 \\
\hline
\end{tabular}

1 The alcohol is expressed in degrees proof at $60^{\circ} \mathrm{F}$.; the concentration of aldehydes, acids, and esters is expressed, respectively, as milligrams of acetaldehyde, acetic acid, and ethyl acetate per $100 \mathrm{ml}$. of sample.

TABLE 7.-Distribution of congenerics in rectifying column for these experimental conditions: Feed-40-percent alcohol at plate 12 ; reflux ratio-5:1; product-plate $42^{1}$

\begin{tabular}{c|c|c|c|c}
\hline \multirow{2}{*}{ Plate } & \multicolumn{3}{|c}{ Congenerics content of 8-hour sample } \\
\cline { 2 - 5 } & Alcohol & Aldehydes & Acids & Esters \\
\hline Heads & 192.9 & 270 & 2.3 & 105.2 \\
50 & 192.9 & 146.3 & .2 & 62.7 \\
46 & 192.4 & 60.9 & .2 & 12.4 \\
42 & 191.4 & 29.6 & 0 & 2.7 \\
40 & 191.0 & 20.0 & 0 & 2.6 \\
38 & 190.5 & 14.8 & 0 & 2.8 \\
36 & 189.6 & 10.4 & 0 & 2.0 \\
34 & - & 8.2 & 0 & 2.8 \\
32 & 188.7 & 6.7 & .1 & 2.1 \\
30 & 188.3 & 5.9 & 0 & 6.7 \\
28 & 186.0 & 6.1 & 0 & 6.8 \\
26 & 184.8 & 5.4 & 0 & 4.7 \\
24 & 183.1 & 4.6 & 0 & 7.6 \\
22 & 180.0 & 4.3 & 0 & 9.9 \\
20 & 178.6 & 2.5 & 0 & 8.8 \\
18 & 174.4 & 4.3 & 0 & 14.4 \\
16 & 166.9 & 4.2 & 0 & 22.4 \\
14 & 154.3 & 3.9 & .1 & 41.2 \\
10 & 71.7 & 1.7 & .1 & 25.1 \\
6 & .8 & 1.5 & 0 & .3 \\
2 & 0 & 1.8 & 0 & .3 \\
\hline
\end{tabular}

3 The alcohol is expressed in degrees proof at $60^{\circ} \mathrm{F}$.; the concentration of aldehydes, acids, and esters is expressed, respectively, as milligrams of acetaldehyde, acetic acid, and ethyl acetate per $100 \mathrm{ml}$. of sample. 
of the column make it unsuitable for use in beverages. Undoubtedly, the esters accumulating in this region of the column are, like fusel oil, less volatile than ethyl alcohol and at the same time virtually insoluble in water. Being less volatile than the alcohol these esters and the fusel oil are forced down from the upper trays by rectification. As they pass down to the bottom of the column they become immisible in the higher water concentrations and steam distillation forces them to rise. Being unable to escape by either end of the column, because of the two opposing effects, these esters and the fusel oil accumulate at same intermediate plates of the column.

It is recognized that, very possibly because of their particular nature, the presence of these esters in the distillate, free from the fusel oil which accumulates with them, would contribute notably to the quality and character of the final product. The presence of high concentrations of the accompaning fusel oil and tail substances, however, will more than offset any benefitial effect. The development of techniques which would allow the recovery of these heavier esters while eliminating the fusel oil and tail substances which accumulate in the same fraction, will be the subject of studies to be conducted in the near future in this Plant.

It can be seen from data presented that, in many instances, the heads product has a somewhat lower alcoholic content than the liquid from the top plate of the column, i.e., plate 50. This is attributed to evaporation losses which occurred while collecting the heads-product stream in an open receiving tank.

\section{CONCLUSIONS}

The results presented in this paper, as well as those presented in a previous publication on the distribution of fusel oil along continuous distillation columns under different operating conditions, indicate that, by removing the main-product stream from a higher point in the column, a lower fusel-oil content is obtained in the main product without sacrificing the recovery of congeneric substances. On the contrary, it can be said that a greater recovery of congenerics could be achieved by removing the product from higher plates at higher proof. Of course, the quantity of congenerics recovered can be controlled by varying the operating conditions such as the size of the heads-stream and the plate from which the main-product stream would be withdrawn. By adequatelly adjusting these operational variables the main product could be varied from a very light alcohol to a rather heavier one containing most of the congenerics present in the raw distillate. Obviously, the latter would be an extreme condition of doubtful convenience because of the very high content of aldehydes that would be obtained in the main product. The data obtained indicate that only in the case of the esters is there some accumulation of these substances 
in the region of high accumulation of fusel oil. The marked adverse effect produced by the extremely high concentration of fusel oil and tail substances found in this region of the column, would more than offset any goodness in the quality of the final product produced by the recovery of these esters.

Utilizing the conventional Barbet continuous-distillation system and operating in such a fashion as to obtain a product of $180^{\circ}$ to $189^{\circ}$ proof, or even less, it is possible to obtain a product of very low concentration of esters, aldehydes, and acids. In any particular case, other conditions, such as the composition of the feed, the number of trays in the column, the feed plate, and the reflux ratio, remaining the same, the product would be lighter in its fusel oil and tail substances content by distilling at a higher proof and withdrawing the product from a higher plate in the column.

Thus, the proof of the distillate would limit the elimination of fusel oil and tail substances which definitely detract from the quality of the product and which are considered by many as more harmful to the health of the public than other congeneric substances, and mostly responsible for "hangover" and other objectionable aftereffects.

During the course of our studies on various phases of the alcoholic distillation from fermented cane molasses it has been found repeatedly that liquids from the bottom and from several trays above the reboiler of continuous distillation columns, which are free from fusel oil and other congeneric substances, still possess the characteristic "tail" odor frequently attributed to fusel oil and which is evidently caused by unidentified substances not accounted for by the classical chemical analysis for esters, acids, aldehydes, and higher alcohols.

In other words, by producing main-product distillates at very high alcoholic content, say $192^{\circ}$ proof, and by properly selecting other operational variables, it is more easily possible to obtain a product containing similar concentrations of esters, acids, and aldehydes than by distilling below $190^{\circ}$ - or below $160^{\circ}$ proof-but with the distinct advantage that the $192^{\circ}$-proof distillate would be lower in its content of fusel oil and tail substances.

Further, with the utilization of extractive distillation technics the use of the proof of the distillate as a criterion for determining whether it is a beverage or a neutral spirit becomes obsolete. By the utilization of extractive-distillation methods it is possible to eliminate virtually all congeneric substances in the extractive distillation column. The dilute product from the extractive-distillation column is fed subsequently into a rectifying column and a distillate at a relatively low alcoholic content can be produced which still would be a neutral spirit due to the virtual absence of congeneric substances. Thus, the elimination of congenerics can be achieved even more completely by the utilization of modern extractive methods. Ac- 
cordingly, it is the opinion of this author that there is no justification for the restriction of the Law regarding the alcoholic content of distillates from molasses, and possibly from other substrates, as a basis for classification as a spirituous beverage or as a neutral spirit.

\section{SUMMARY}

The results of these studies on the distribution of congeneries along continuous distillation columns, as well as previously published results on the distribution of fusel oil under different operating conditions, indicate the convenience of distilling at the highest possible proof within the limits established by the Law. By distilling at higher proof, and by properly selecting other operational variables, it is possible to recover congeneric substances to any desired extent while reducing the content of fusel oil and unidentified tail substances in the main product. It is recognized that the presence of the latter detracts from the quality of alcoholic beverages.

\section{RESUMEN}

Los resultados de estos estudios sobre la distribución de congenéricos a lo largo de las columnas de destilación, así como resultados publicados anteriormente sobre la distribución de concentraciones de aceite de fúsel bajo diferentes condiciones de operación, señalan la conveniencia de destilar al grado prueba más alto que sea posible dentro de los límites fijados por la Ley. Destilando a alta prueba y seleccionando adecuadamente las demás variables de operación, es posible recuperar con el producto principal substancias congenéricas en la medida que se desee, mientras se reduce el contenido de aceite de fúsel y de otras substancias no identificadas y que son responsables del olor y sabor a colas en la destilación alcohólica.

\section{LITERATURE CITED}

1. Brau, H. M., Fusel Oil in the Alcoholic Distillation; Experimental Data on its Distribution by Plates of Continuous Distillation Columns Under Different Operating Conditions, Univ. P.R. Agr. Exp. Sta. Tech. Paper 24, 1958.

2. -, Automatic Controls in Continuous Alcoholic Distillation, Univ. P.R. Agr. Exp. Sta. Tech. Paper 18, 1957. 